\title{
A Colour Atlas of Nursing Procedures in Accidents \& Emergencies
}

By J. B. BACHe, C. R. Armitt \& J. R. Tobis

Wolfe Medical Publications Ltd, London. 1985. 151pp. $£ 12.00$.

The Wolfe colour atlases have an established reputation for high-class photography, excellent presentation and thoroughly reliable text, carefully ordered according to a consistent pattern. This volume is no exception; it meets all the norms effortlessly and effectively.

They are in the same literary class as operation and maintenance manuals for cars, washing machines and so on, and are open to the same criticisms. More so, in fact, than their mechanical equivalents as they are not applicable to machines, nor for the use of mechanics. If they have an educational value it lies in their brilliant illustrations. The aim of the educational process is to teach people to think, not to train mechanics to mind machines. The latter may be equally important, but it is certainly different.

Thus, you can hardly explain nasal packing without a diagrammatic lateral view of the nasal cavity appropriately packed. No more can you teach the application of any support or dressing except in terms of its purpose and effects. There is no room for these discursive elements in this type of presentation. It would be easy to go through the text item by item finding fault with details: for instance, what an opportunity for showing the application of a hanging ' $U$ ' plaster for the treatment of fractured shaft of humerus has been missed! Further, how odd to apply strapping supports over cotton bandages when more than half their value arises from their adhesion to the skin! But, as the use of such an atlas can only properly be as an educational aid, its illustrations an instructions merely providing a skeleton for true education by discussion and practice there is no need to cavil over details.

$\mathrm{Mr}$ Bache and his colleages are to be congratulated on the skill and excellence of their photography, and the care and precision of their text, but your reviewer has to express the hope that the atlas will never be regarded by nursing pupils, medical students or junior qualified staff as a dogmatic educational text to help them through the perilous seas of daily patient care. An operational manual must never be allowed to replace true education and apprenticeship.

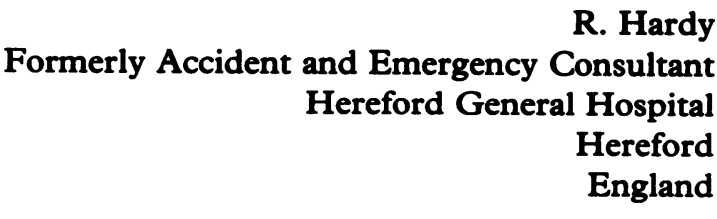

England 